\title{
The New DIN Standards in Earth Building-The Current Situation in Germany
}

\author{
Horst Schroeder \\ Dachverband Lehm e. V. (DVL), Weimar, 99425, Germany
}

\begin{abstract}
In the last decade the use of earth in construction has become increasingly widespread in many countries. Building with earth can contribute to sustainable development by reducing environmental impact compared with other building materials or systems. This new consciousness has given rise to a growth in the number of earth building standards in recent years although, in absolute terms, the number is very small compared with other typical building materials and systems. Forty different earth building standards coming from 20 different countries were examined. The standards provide varying degrees of technical information. With regard to their scope of application, the documents can be classified into three types, each of them dealing with a particular aspect: soil classification, earth building materials, earth construction systems. In Germany, a revival of building with earth first came about in the 1980s as an awareness of ecological criteria grew. A product of this development was the elaboration of an earth building standard, the "Lehmbau Regeln" by the Dachverband Lehm e. V., the German national earth building association. That part of the "Lehmbau Regeln" concerning earth blocks and earth mortars was adapted to the circumstances of national DIN/European building codes and published in August 2013 as DIN 18945-47. A new DIN 18948 "Earth boards" will be issued in 2019. The four DINs were elaborated for industrially produced, chemically non-stabilized earth building materials.
\end{abstract}

Key words: Standards, Germany, international, DIN.

\section{Introduction}

Traditional earth building was practised over hundreds or even thousands of years on the basis of local experience with tried and tested building materials and construction methods. The suitability of a soil for building purposes was judged by the local masters, based on experience. Their accumulated technical knowledge was passed on from generation to generation.

Building today is a complicated commercial process characterised by legalised agreements between all participants - the client, the contractor, the architect, the building materials manufacturer etc. For commercial building projects, all materials and structures have to conform to building standards and regulations. Material properties must be reproducible in standardised test procedures. This also applies to

Corresponding author: Horst Schroeder, Dr. Eng., Bauhaus University Weimar/Dachverband Lehm e. V., Germany, research field: planning and building with earth. quality control in the production of earth building materials and structures.

In most countries around the world, building with earth is primarily a traditional or "non-engineered" form of construction and lacks standards. In countries where no standards exist, building with earth lacks a legal framework for use in commercial projects.

In the last decade, however, the use of earth in construction has become increasingly widespread in many countries. Young architects in particular have discovered new ways of working, designing and building with this traditional material. Soil as a raw material for building purposes can be found in significant quantities in numerous regions of the world and many consumers, architects and producers of building materials value the favourable ecological properties of earth building materials and their contribution to sustainable development. This new consciousness has given rise to a growth in the number of earth building standards in recent years, although in 
absolute terms the number is very small compared with other typical building materials and systems.

Building with earth can contribute to sustainable development by reducing environmental impact compared with other building materials or systems. This aim can only be achieved by elevating earth building to an "engineered" building system based on building standards issued by national standards organisations. The ecological quality of earth building materials can be declared and compared with other building materials by EPD (Environmental Product Declarations).

\section{International Situation}

Forty different standards from 20 different countries and regions were examined [1]. The standards provide varying degrees of technical information. With regard to their scope of application, the documents can be classified into three types, each dealing with a particular aspect:

- Soil classification,

- Earth building materials,

- Earth construction systems.

Our analysis shows that standard, internationally accepted terminology is still lacking. This, however, is an essential general prerequisite for developing standards and normative documents.

In those countries that do have established standards, there are usually three types of documents that govern the degree of implementation in the system of national building codes:

(1) Standards and regulations issued by NSBs (national standards bodies),

(2) Normative documents issued by local/national organisations,

(3) Technical documents.
For earth building to be integrated into national standards, the highest degree of implementation, the materials and techniques usually have to pass a general process of approval with the NSB:

- Draft development by a group of specialists ("the technical committee") with proven competence in building with earth,

- Draft presentation to a broad range of specialists with a view to reaching a consensus between them,

- Presentation of the "consensus draft" to the NSB for final approval,

- In Europe the draft has to pass the EC Bureau for Standards for certification,

- Publishing in a state decree.

Table 1 provides an overview of the countries that have established earth building standards and norms. The subjects most frequently covered in the earth building standards are:

(a) Building materials/techniques: adobe, CEBs (compressed earth blocks), rammed earth, timber-framed structures with earth infill.

(b) Material properties: texture, plasticity/binding strength, natural constituents (organic, lime, salt content), shrinkage, compatibility, classification, test results, safety performance.

(c) Local conditions: earthquake damage.

Special handbooks dealing with conservation of traditional/historical earthen architecture in earthquake-damaged regions were issued by NSB and/or official bodies in Chile, Italy and Morocco.

Compared with other "normal" building materials, the field of earth building is less well defined and there is a general lack of standardized test procedures for determining soil parameters for earth building purposes. Most such tests have been adopted from other fields (concrete, soil mechanics, ceramics etc.) that were not

Table 1 An overview of countries with established standards for earth building.

\begin{tabular}{ll}
\hline Type of standard & Country \\
\hline NSB & Brazil, Colombia, Germany, France, India, Kenya, Kyrgyzstan, Nepal, New Zealand, Nigeria, Peru, \\
Normative doc & Spain, Sri Lanka, Tunisia, Turkey, USA (New Mexico, California), Zimbabwe \\
Technical doc & Australia, Spain, Switzerland, Germany \\
\hline
\end{tabular}


originally devised for earth building and only partially take into account their particular properties. In order to develop building with earth into an "engineering" building method the development of material-specific building standards is necessary.

\section{The German Standards for Building with Earth}

The development of standards for building with earth has a long tradition in Germany that reaches as far back as the 16th century in different German Federal States. As a result of the rapid growth of cities, two main problems developed with regard to building at this time: Timber as a prevailing building material became scarce and it was not fire-resistant. These constraints limited the use of timber, so earth was increasingly used as a building material.

In the last century the first German earth building standards were introduced in 1951 by the German NSB as DIN 18951 based on a draft drawn up in 1944. Increased industrialized production of building products displaced the production of earth-based building materials and earth building all but died out for over three decades. DIN 18951 was withdrawn in 1971 and not replaced.

A revival of building with earth first came about in Germany in the 1980s as an awareness of ecological criteria grew. A product of this development was the creation of an earth building standard, the "Lehmbau Regeln" by the Dachverband Lehm e. V. (DVL), the German national earth building association [2]. This standard was approved by the German National Building Authority in 1999 and 2008. The main aspects covered by this standard are:

- The selection of soils suitable for building purposes using testing procedures,

- Earth building materials: definition of testing procedures and qualities,

- Earth building structures: definition of construction, technologies, testing procedures and qualities.
Special attention must be given to load-bearing structures. The standards stipulate permissible strength parameters, including a safety coefficient for the calculation of walls made of rammed earth, cob or earth blocks. Normative physical parameters for the different earth building materials also allow the thermal and physical performance of building elements to be calculated, so that heating and insulation schemes can be drawn up and submitted for approval by the appropriate authorities.

\section{The German DIN Earth Building Standards}

In future, all European national standards will be replaced by European (EN) or international (ISO) norms in response to the process of convergence in regulations. In the context of building products, this will be achieved by the "Regulation of the European Parliament and the Council for the Marketing of Construction Products" of April 2011 [3].

The aim of this document is to foster the free movement and use of construction products in the internal European market, emphasised by the use of a common technical language and clear terms for applying the CE mark. The CE mark guarantees defined qualities and reproducible testing procedures for quality control of the industrial production process of building products.

For the conversion period, national marks will be accepted in the EU which guarantees standards for material properties and reproducible testing procedures for the quality control of the production process. In Germany, this is the "Ü mark" (conformity mark).

The "Lehmbau Regeln" developed by the DVL did not meet this requirement. Therefore, the DVL had prepared standard drafts for industrially produced chemically non-stabilized (i.e. no artificial binders) earth building materials.

In June 2011, the DVL tendered an application for the formation of an earth-building task force 
(Technical committee TC) "Lehmbau" to the German Standards Institute (DIN). The compiled and agreed draft texts were included into this application as a basis for discussions on the preliminary standard by the DIN. The constitutive meeting for DIN TC "Lehmbau" (NA 005-06-08 TC "Lehmbau") took place on 23rd September 2011. The DIN drafts to be developed were given the following titles:

- DIN 18945 Earth blocks - terms, requirements, test methods.

- DIN 18946 Earth masonry mortars-terms, requirements, test methods.

- DIN 18947 Earth plaster mortar-terms, requirements, test methods.

The formulation of the draft DIN (E) 18945-47 was brought to completion with DIN NA "Lehmbau" in July 2012, followed by a four-month public disclosure period for discussion. After dealing with raised objections, the drafts were published as DIN regulations on 1st August 2013.

A new DIN 18948 "Earthen boards" will be issued in 2019. The chapters "Terms" and "Conformity Assessment" of the four DINs will be concentrated in two new DINs which will be issued also in 2019:

- DIN 18942-1 Earthen materials-Part 1: Vocabulary.

- DIN 18942-100 Earthen materials-Part 100: Conformity assessment.

\subsection{General Requirements}

DINs 18945-48 follow the general formal and content requirements for the formulation of DIN regulations for building products. They contain the following sections:

- Range of application/normative references.

- Application classes/requirements.
- Description/identification.

- Testing.

- Delivery certificate/product data sheet.

- Appendix (informative).

The DIN standards include procedures for declaration of product essential features and consider aspects of Life Cycle Assessment (LCA) for sustainable building.

\subsubsection{Area of Application}

The area of application of DIN 18945-48 covers industrially and works-produced earth-building products without the use of chemical stabilizers. For the use/application of earth-building products the "Lehmbau Regeln" continues to apply.

Special application classes (AK) relating to possible dampness interaction in a built-in condition were only formulated for earth blocks (DIN 18945).

\subsubsection{Essential Features}

Building products which accord with EU V 305/2011 [3] are those products/building component sets, which are manufactured and supplied for inclusion in permanent structures or parts thereof, and their performance influences the performance of the building with regard to basic requirements for built structures. The basic requirements for built structures include:

(1) Mechanical strength and stability.

(2) Fire protection.

(3) Hygiene, health and environment protection.

(4) Safety and barrier-free access in use.

(5) Sound protection.

(6) Energy-saving and thermal insulation.

(7) Sustainable use of natural resources.

(Sustainable in the sense of Ref. [3]: Recycling ability, permanence and use of environmentally compatible raw and secondary building materials).

Table 2 Application classes for works-manufactured earth blocks (EB).

\begin{tabular}{ll}
\hline Area of application & AK \\
\hline Rendered, exposed external masonry in fare-faced timber-framed walls & Ia \\
Continuously rendered, exposed external masonry & Ib \\
Clad or otherwise constructed weather-protected external and internal masonry & II \\
Dry applications (e.g. deck infill, stacked walls) & III \\
\hline
\end{tabular}


Buildings in their entirety and in their component parts must be suitable for the proposed use, particularly with regard to the health and safety of all persons involved with buildings during their entire life cycle. Buildings must satisfy these basic requirements provided that they are correctly maintained over an economically appropriate period of time.

Essential features are those features of a building product, which relate to the basic requirements of a building with regard to their relevant essential features. These are expressed in steps or classes or in a description and are declared by the product manufacturer. Basic requirements 1 and 2 of the listing with the relevant essential features have priority.

Strength characteristics:

Assessments of strength characteristics for the differing demands made on earth-building materials are categorized in strength classes (CS) with standardized test procedures (Tables 3-5):

Earth blocks of Class of use Ib and II (Table 2) can be used in load-bearing situations if their minimal
Class of Block CS is 2. Laboratory test values are not allowed to fall below the mean and smallest single CS values.

Fire performance:

With regard to fire performance, building material classes of earth building materials (EB, CMM, CRM) are categorized according to DIN 4102-1:1998-05. According to DIN 4102-4 earth-building materials with a content of homogenously distributed organic aggregates or fibers of $\leq 1$ mass $/ \%$ can be classified in building material class A1 (fire resistant) without testing.

Building material definition/identification:

In Chapters 5 "Requirements" of DIN 18945-47 essential features are defined with regard to the earth-building material. These features must be declared by the manufacturer and be part of the definition/identification of earth-building materials. Table 6 gives an overview of the relevant essential features.

In Chapter 6 of DIN 18945-48, the essential features

Table 3 Compressive Strength classes (CS) for earth blocks (EB) in accordance with DIN 18945.

\begin{tabular}{lll}
\hline Class of block compressive strength CS & Compressive strength MV N/mm & Compressive strength SSV N/mm ${ }^{2}$ \\
\hline 2 & 2.5 & 2.0 \\
3 & 3.8 & 3.0 \\
4 & 5.0 & 4.0 \\
5 & 6.3 & 5.0 \\
6 & 7.5 & 6.0 \\
Test procedure & DIN EN ISO 7500-1:2004-11 & DIN EN ISO 7500-1:2004-11 \\
\hline
\end{tabular}

MV: Mean value; SSV: Smallest single value.

Table 4 Strength classes (SC) for earth masonry mortar (EMM) in accordance with DIN 18946.

\begin{tabular}{lll}
\hline Strength class SC & Compressive strength, N/mm & Adhesive shear strength, N/mm ${ }^{2}$ \\
\hline M0 & - & \\
M2 & $\geq 2.0$ & $\geq 0.04$ \\
M3 & $\geq 3.0$ & \\
M4 & $\geq 4.0$ & DIN EN 1052-3: 2007-06 \\
Test procedure & DIN EN 1015-11:2007-05 & \\
\hline
\end{tabular}

Table 5 Strength classes (SC) for earth plaster mortar (EPM) in accordance with DIN 18947.

\begin{tabular}{llll}
\hline Strength class SC & Compressive strength N/mm & Tensile strength N/mm & Adhesive strength N/mm ${ }^{2}$ \\
\hline S I & $\geq 1.0$ & $\geq 0.3$ & $\geq 0.05$ \\
S II & $\geq 1.5$ & $\geq 0.7$ & $\geq 0.10$ \\
Test procedure & DIN EN 1015-11:2007-05 & DIN EN 1015-11: 2007-05 & DIN EN 1015-12: 2007-05 \\
\hline
\end{tabular}


for the respective earth-building material are determined, which carry the building material description $(\bullet)$ in an established order. All the data that must be declared $(\bullet \circ)$ are identified on a product data sheet. Data regarding delivery must be documented on a delivery sheet.

Forming procedure:

The earth block sizes are defined according to the DIN standard for brickwork (NF, DF, x DF). The dry density classes are given in $\mathrm{kg} / \mathrm{m}^{3}$. The types of block molding are defined by abbreviations in Table 7 .

Identification example for:

Compression molded, structural earth block without perforations, compressive strength class 3 , use class Ia, bulk density class 1.6 , length $240 \mathrm{~mm}$, width $115 \mathrm{~mm}$ and height $71 \mathrm{~mm}$ (normal format NF).

Earth block-structural-DIN 18945-LS p 3-Ia-1.6NF.

\subsection{Building Control/Certificate of Conformity}

Earth-building materials must be assessed with regard to their performance in relation to their essential features using the test systems indicated in DIN Chapters 8 or 9 .

The declaration of performance reliability of the tested building products with regard to their essential features will be regulated in a new standard DIN 18942-100 Conformity assessment. This standards includes the earth building materials according to DIN 18945-48 (EB, EMM, EPM, EP).

Table 6 Relevant essential features in the description/identification of industrially produced earth-building materials according to DIN 18945-48.

\begin{tabular}{|c|c|c|c|c|c|}
\hline No. & Essential feature & $18945 \mathrm{~EB}$ & $18946 \mathrm{EMM}$ & $18947 \mathrm{CRM}$ & $18948 \mathrm{EP}$ \\
\hline 01 & Clay mortar type in the delivered form (wet/dry) & & ० & ○ & \\
\hline 02 & Raw material mineral/organic & $\bullet$ & $\bullet$ & $\bullet$ & ○ \\
\hline 03 & Granular group (upper sieve grade D) & & $\bullet$ & $\bullet$ & \\
\hline 04 & Oversized particle & & ० & ○ & \\
\hline 05 & Shape/dimensions (height for EP)/perforation & $\bullet$ & & & $\bullet$ \\
\hline 06 & Forming procedure & $\bullet$ & & & ○ \\
\hline 07 & Bulk density class (for EMM and EPM of set mortar) & $\bullet$ & $\bullet$ & $\bullet$ & $\bullet$ \\
\hline 08 & Linear shrinkage co-efficient & & o & ○ & \\
\hline 09 & Size tolerance class & & & & $\bullet$ \\
\hline 10 & Type of edges / surfaces & & & & ० \\
\hline 11 & Type of reinforcing (integrated mats) & & & & o \\
\hline 12 & Special delivery characteristics & & o & ○ & \\
\hline 13 & Strength class (SC) acc. to Tables 3-5 & $\bullet$ & $\bullet \circ$ & $\bullet \circ$ & \\
\hline 14 & Surface hardness / Surface tensile strength / flexural strength & & & & o \\
\hline 15 & Building material fire resistance class & ○ & ० & ○ & ० \\
\hline 16 & Freeze and thaw behavior & ○ & & & \\
\hline 17 & Thermal conductivity & ○ & ○ & ○ & ○ \\
\hline 18 & Thermal capacity & & & & o \\
\hline 19 & Vapor diffusion resistance & ○ & ○ & ○ & ○ \\
\hline 20 & Structural function (structural/non-structural) & $\bullet$ & & & \\
\hline 21 & Use class & $\bullet$ & & & $\bullet$ \\
\hline 22 & Abrasion resistance & & & ○ & \\
\hline 23 & Water vapor adsorption & $\square$ & $\square$ & $\square$ & $\square$ \\
\hline 24 & $\mathrm{CO}_{2}$-equivalent value & $\square$ & $\square$ & $\square$ & $\square$ \\
\hline 25 & Natural radioactivity & $\square$ & $\square$ & $\square$ & $\square$ \\
\hline
\end{tabular}

- Feature included in the building material description.

o Feature also included in the identification (product data sheet).

$\square$ Feature optional, also included in the identification (product data sheet). 
Table 7 Types of earth block molding.

\begin{tabular}{lllll}
\hline Type of block molding & Mechanically “thrown” & Compressed & Extruded & Perforated \\
\hline Abbreviation & $\mathrm{f}$ & $\mathrm{p}$ & $\mathrm{s}$ & $\mathrm{g}$ \\
\hline
\end{tabular}

\subsection{Ecological Features}

Ecological features of the earth building materials according to DIN 18945-48 are considered in corresponding Appendixes $\left(\mathrm{CO}_{2}\right.$ equivalent) of each norm. On the base of these information, a new type of technical documents for earth building materials, the Environmental Product Declarations (EPD), will be developed by the DVL. EPDs are voluntary standards, commitments or guarantees provided by producers, organizations, and quality assurance associations that document the environmental performance of (earth) building products in the form of a certificate awarded by external bodies.

EPDs for building products are:

- developed by LCA experts and producers (of earth building products) on an accepted and universal basis,

- verified by an independent third party (certificate),

- contain environmental aspects (Life cycle analyses LCA) of the (earth) building product alongside "performance aspects", e.g. technical, social and economic performance.

The preliminary stage of an EPD is the development of Product category rules (PCR) for the specific product category based on a standardized life cycle assessment (LCA) procedure according to DIN EN ISO 14040/DIN EN ISO 14025/DIN EN 15804. PCR for EB, EMM, EPM and EP were developed by the DVL as result of a project 2016-2018 supported by the German Environmental Foundation DBU and published at www.dachverband-lehm.de/wissen/PKR-UPD.

\section{Future Perspective}

With regard to the development of new DIN standards for earth building, the following trends can be observed:
Building material standards need to be developed for more earth building products. A new standard DIN 18948 Clay panels will be expected in 2019. Ready-to-use mixes, for example, for rammed earth are currently under discussion.

The building material standards need to be followed by processing standards. Here, an important aspect will be to define partial safety factors for load-bearing structures made of earth building materials. With the official introduction of the Eurocodes EC 1-9 as DIN EN 1990-1999 on July 1, 2012, this approach has become mandatory for the dimensioning of load-bearing structures using earth building materials.

The DIN standards for earth building must be integrated into corresponding European or national application standards (which might still exist concurrently) as separate chapters on earth building. This has been done in the case of DIN 18550-2:2015-06 Design, preparation and application of external rendering and internal plastering or DIN EN 13942-2. Currently, earth blocks and EMM are not integrated in DIN EN 1996-1-1.

The Lehmbau Regeln needs to be adjusted to reflect current changes. They will continue to cover "earth building activities on site" in terms of building inspection, whereas the DIN standards will be applied to the production and processing of industrially manufactured earth building materials.

After five years of successful working, currently the DINs 18945-47 are revised. There will be some structural changes: In future, the chapters "Definitions" of the DIN 18945-48 will be summarized in a new standard DIN 18942-1 Earthen materials-Part 1: Vocabulary and, correspondingly, the chapters "Conformity assessment" in a new standard DIN 18942-100 Earthen materials-Part 100: Conformity assessment. The revised "old" and new standards are 
expected in 2019.

The DVL will consider in their task, to continue to accompany, organize and direct the process of developing DIN standards for earthen building in the future. How long it will take to accomplish this task depends on many factors, not least on the available materials and the personnel resources of the association. The experience gained in the development of the now existing DIN standards will undoubtedly be of great assistance.

\section{References}

[1] Schroeder, H. 2016. Sustainable Building with Earth. Cham/Heidelberg/New York/Dordrecht/London: Springer Int. Publ.

[2] Dachverband Lehm e. V. (ed.). 2009. Lehmbau Regeln-Begriffe, Baustoffe, Bauteile. 3rd edition. Wiesbaden: Vieweg+Teubner|GWV Fachverlage GmbH.

[3] Regulation (EU) No. 305/2011 of the European Parliament and of the Council of 9 March 2011. "Laying down Harmonized Conditions for the Marketing of Construction Products and Repealing Council Directive 89/106/EEC." Official Journal of the European Union L 88/5 of 4.4.2011. 